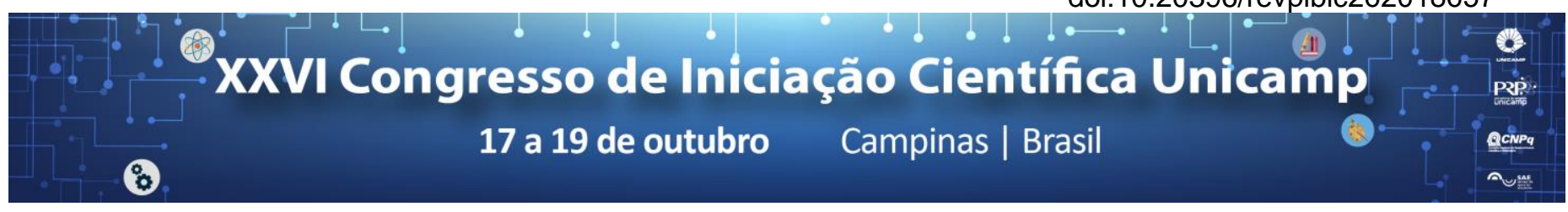

\title{
O DESENVOLVIMENTO REGIONAL NO VALE DO RIO SÃO FRANCISCO
}

\author{
Jennifer Ribeiro da Silva, Fernando Cezar de Macedo Mota
}

\begin{abstract}
Resumo
A região do Vale do São Francisco, tendo como eixo central as cidades de Petrolina-PE e Juazeiro-BA, passou por grandes mudanças nas últimas décadas, tornando-se um importante polo de fruticultura irrigada no país, voltada, principalmente, para a exportação. As transformações se deram através de investimentos públicos e privados ocorridos a partir da segunda metade do século XX, promovendo grandes impactos econômicos e sociais na região.
\end{abstract}

\section{Palavras-chave: \\ Fruticultura irrigada, polo Petrolina-PE/Juazeiro-BA, semiárido.}

\section{Introdução}

Uma série de ações governamentais são promovidas a partir de 1950 no Nordeste brasileiro com o intuito de combater os efeitos da seca e promover o desenvolvimento econômico da região, sendo os projetos de irrigação um dos principais instrumentos para atingir esse objetivo. A partir da criação de importantes órgãos do Estado como a SUDENE e a CODEVASF, que implantou uma série de perímetros irrigáveis na região, 0 Vale do São Francisco se torna um importante polo de fruticultura irrigada para exportação no país, tendo como principal eixo de produção as cidades de Petrolina-PE e Juazeiro-BA. Deste modo, este trabalho tem como principal objetivo mostrar como o Vale do São Francisco se tornou uma das regiões agrícolas mais dinâmicas do país e refletir se esse processo significou uma melhoria da qualidade de vida da população.

\section{Resultados e Discussão}

A região do Vale do São Francisco nem sempre foi conhecida por ser um grande polo de fruticultura irrigada. Historicamente, a atividade agrícola predominante na região era a de subsistência, com a plantação de espécies de ciclo curto. Este cenário sofre alteração a partir de 1950 com a realização de uma série de investimentos públicos em projetos de irrigação e infraestrutura para a região, a partir da criação de importantes órgãos como a SUDENE em 1959 e a CODEVASF em 1974. É a partir de então que se começa a gestar a fruticultura irrigada na região, sendo Petrolina-PE e Juazeiro-BA os munícipios centrais.

A implantação de Projetos Públicos de Irrigação a partir de 1970 leva a uma grande expansão da fruticultura irrigada, que passa por um movimento de crescimento e diversificação, processo que se consolidaria após a crise econômica brasileira de 1980. Com a crise, o Estado deixa de aplicar recursos no setor agrícola e isso faz com que a iniciativa privada se estabeleça na região, favorecida pelos incentivos fiscais, promovendo uma grande alteração na dinâmica local. A fruticultura ampliase cada vez mais, e passa a ser marcada por uma alta especialização e por uma maior tendência à produção de culturas como a manga e a uva, devido a sua capacidade de gerar grandes lucros e de aceitação pelos mercados consumidores internacionais.

O cultivo de manga e uva atrai uma série de investidores do Sul e Sudeste do país, havendo uma completa mudança no perfil dos agricultores da região, que passam a ser caracterizados por sua aptidão técnica e de investimentos na fruticultura irrigada, enquanto o pequeno produtor agrícola local se vê excluído desse processo, já que não consegue sustentar o negócio em virtude do alto custo de produção dessas culturas. Dentro dessa nova estrutura produtiva, é criada a Associação dos Exportadores de Hortifrutigranjeiros e Derivados do Vale do São Francisco (Valexport) em 1988, em função da necessidade de uma maior organização entre os produtores, sendo fundamental para a consolidação e desenvolvimento da fruticultura irrigada na região.

Deste modo, o eixo Petrolina e Juazeiro se consolida como um importante polo de fruticultura irrigada. A região produz atualmente cerca de 604 mil toneladas de manga e 252 mil toneladas de uva por ano, sendo a Europa e Estados Unidos seus principais mercados consumidores (Lima, 2017). Dados do IBGE de 2013 mostram que o Produto Interno Bruto do submédio do São Francisco era de $R \$ 9,85$ bilhões, sendo $67,8 \%$ desse total gerado pelos municípios de Petrolina (44,2\%) e Juazeiro (23,6\%) (Viana, 2017).

\section{Conclusões}

Uma série de fatores contribuíram de maneira decisiva para a consolidação do Vale do São Francisco como um grande polo de fruticultura irrigada no Brasil. Entre eles, a presença de um clima altamente favorável na região para a produção de frutas, bem como os grandes investimentos públicos aplicados na região a partir de 1950, que fizeram dela um grande foco de investimentos privados a partir de 1980. Mas apesar do grande sucesso dos projetos de desenvolvimento implantados na região, eles ainda se caracterizam por serem excludentes, deixando a margem grande parte da população do Vale do São Francisco.

\footnotetext{
SILVA, Pedro Carlos Gama da. Articulação dos interesses públicos e privados no Pólo Petrolina-PE/Juazeiro-BA: Em busca de espaço no mercado globalizado de frutas secas. 2001. 258f. Tese de Doutorado - Universidade Estadual de Campinas, 2001.

LIMA, ALANA. No Vale do São Francisco, Censo Agro colhe dados de frutas que ganham o mundo. Agência IBGE Notícias, Pernambuco, 11 dez.2017. VIANA, ANA CAROLINA D’ÁVILLA (org). Política, Planejamento e Gestão das Regiões e Redes de Atenção à Saúde no Brasil. Relatório Regional. Petrolina e Juazeiro: Regiões e Redes, 2017. Disponível em: < http://www.resbr.net.br/wpcontent/uploads/2017/06/dossie_petrolina_juazeiro_a_regiao.pdf $>$. Acesso em: 15 jul. 2018
} 